\title{
Introduction and Classification of Childhood Diarrhoea
}

\author{
Angela Ine Frank-Briggs \\ University of Port Harcourt Teaching Hospital, Port Harcourt, Rivers State, \\ Nigeria
}

\section{Introduction}

\subsection{Diarrhoea is a global problem}

Diarrhoea is one of the most common causes of morbidity and mortality in children worldwide. The word diarrhoea is derived from the Greek "diarrhoia", meaning to flow through. In clinical terms, diarrhoea refers to either an increased stool frequency or a decreased stool consistency, typically a watery quality. The World Health Organization (WHO) defines a case as the passage of three or more loose or watery stools per day. Nevertheless, absolute limits of normalcy are difficult to define; any deviation from the child's usual pattern should arouse some concern (particularly when the passage of blood or mucus, or dehydration occurs) regardless of the actual number of stools or their water content.

Diarrhoeal illness is the second leading cause of child mortality; among children younger than 5 years, it causes 1.5 to 2 million deaths annually. In 1982, on the basis of a review of active surveillance data from studies conducted in the 1950s, 1960s and 1970s, it was estimated that 4.6 million children died annually from diarrhoea. In 1992, a review of studies conducted in the 1980s suggested that diarrhoeal mortality had declined to approximately 3.3 million annually. It was noted that children in the developing world experienced a median of between two and three episodes of diarrhoea every year. Where episodes are frequent, young children may spend more than $15 \%$ of their days with diarrhoea. About $80 \%$ of deaths due o diarrhoea occur in the first two years of life. The main cause of morbidity from acute diarrhoea is dehydration, which results from loss of fluid and electrolytes in the diarrhoeal stools. In severe cases this could lead to vascular collapse, shock and eventually death. Other causes of death include malnutrition from loss of nutrients from the stool, effects of infection on metabolism and the withholding or modification of food during diarrhoea which is a common practice.

Diarrhoeal illnesses may have a significant impact on psychomotor and cognitive development in young children. Early and repeated episodes of childhood diarrhoea during periods of critical development, especially when associated with malnutrition, co-infections, and anemia may have long-term effects on linear growth, as well as on physical and cognitive functions.

Worldwide childhood death secondary to diarrhoea declined from an estimated five million per year in 1980 to less than two million in 1999. The decline is generally attributed to global 
improvements in sanitation and the use of oral rehydration therapy, as well as zinc and vitamin A therapy.

In developing countries, infants experience a median of six episodes annually; children experience a median of three episodes annually. Diarrhoeal illness may consist of acute watery diarrhoea, invasive (bloody) diarrhoea, or chronic diarrhoea (persistent $\geq 14$ days). The major causes and the prevalence of chronic diarrhoea differ between developed and developing countries. In the developing world, chronic diarrhoea is typically associated with serial enteric infections and malnutrition; it is manifested by a chronic enteropathy, with impaired mucosal healing and diminished digestive and absorptive capacity.

In developed countries, children are less likely to be exposed to serial enteric infections and malnutrition. In these populations, chronic diarrhoea is more likely to be induced by underlying disease causing malabsorption or maldigestion. However, enteric infections (particularly in immunocompromised patients), malnutrition, and dietary factors (eg, excessive consumption of juice), play a role in some cases. Figure 1 below shows the relationship between malnutrition and diarrhoea.

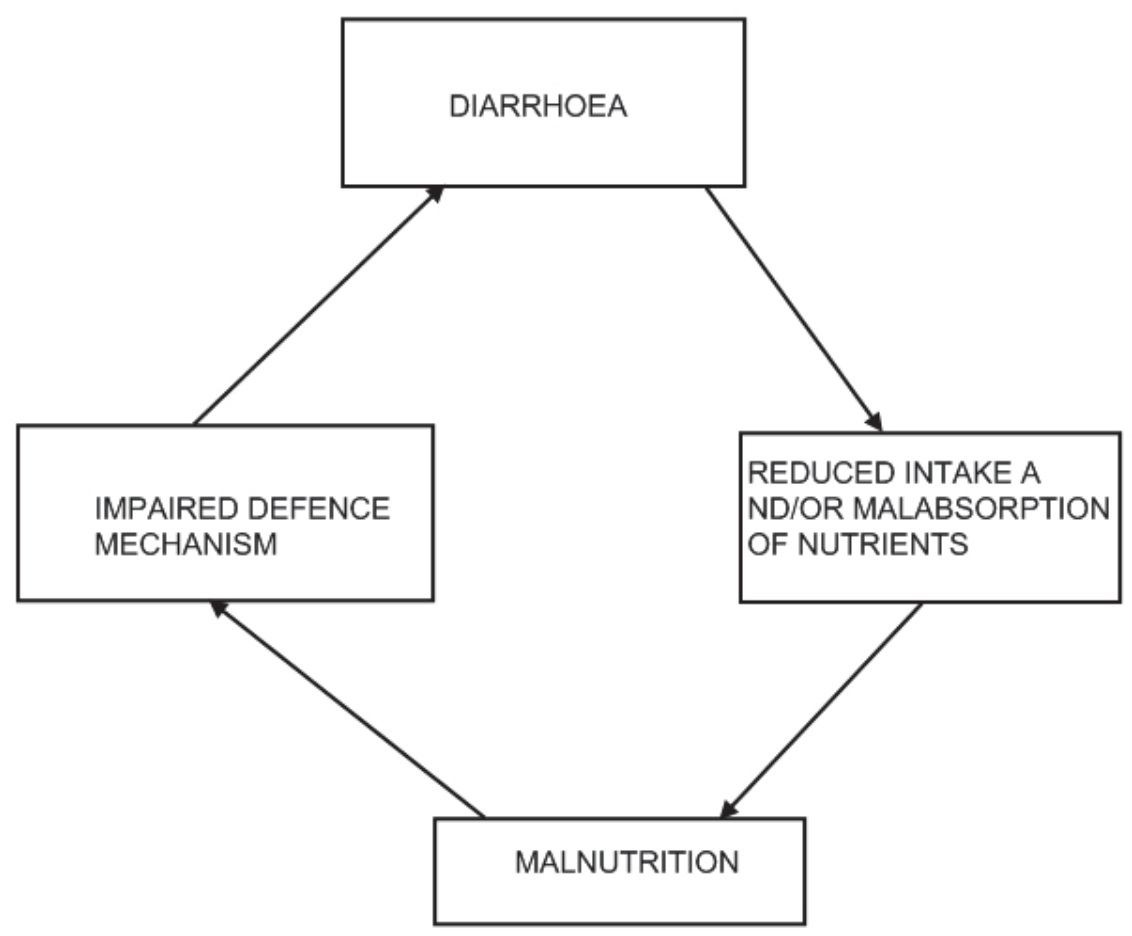

Fig. 1. The vicious cycle of diarrhoea and malnutrition.

\section{Classification of diarrhoea}

Classification facilitates the approach to management of childhood diarrhoea.

Issues related to the etiology, clinical assessment, treatment, and prevention of different types of diarrhoea are better analyzed when classified. 
Diarrhoea is defined in epidemiological studies as the passage of three or more loose or watery stools in a 24- hour period; a loose stool being one that would take the shape of the container. Exclusively breastfed infants normally pass several soft, semi-liquid stools; for them, it is practical to refer to diarrhoea as an increase in stool frequency or liquidity that is considered abnormal by the mother.

Diarrhoea can be classified based on duration of each diarrhoeal episode, aetiological factor, pathophisiological mechanism and systemic diseases contributing to diarrhoea.

The distinction, supported by the World Health Organization (WHO), has implications not only for classification and epidemiological studies but also from a practical standpoint because protracted diarrhea often has a different set of causes, poses different problems of management, and has a different prognosis.

\section{Classification based on duration}

\subsection{Acute watery diarrhoea}

This term refers to diarrhoea that begins acutely, lasts less than 14 days (most episodes last less than seven days), and involves the passage of frequent loose or watery stools without visible blood. Vomiting may occur and fever may be present. Acute watery diarrhoea causes dehydration; when food intake is reduced it also contributes to malnutrition. When death occurs, it is usually due to acute dehydration. The most important causes of acute watery diarrhoea in young children in developing countries are rotavirus, enterotoxigenic Escherichia coli, Shigella, Campylobacter jejuni, and Cryptosporodium. In some areas vibrio cholerae 01, Salmonella and enteropathogenic E. Coli are also important.

\subsection{Persistent diarrhoea}

This is diarrhoea that begins acutely but is of unusually long duration (at least 14 days). The episode may begin either as watery diarrhoea or as dysentery. Marked weight loss is frequent. Diarrhoeal stool volume may also be great, with a risk of dehydration. There is no single microbial cause for persistent diarrhoea; enteroadherent E. coli, Shigella and Cryptosporidium may play a greater role than other agents. Persistent diarrhoea should not be confused with chronic diarrhoea, which is recurrent or long lasting diarrhoea due to non infectious causes, such as sensitivity to gluten or inherited metabolic disorders.

\subsection{Intractable (protracted) or chronic diarrhoea}

Is a term applied to diarrhoea episodes which are of long duration, (more than 4 weeks), for which no known cause can be found and which does not respond to specific or non specific form of treatment. Chronic diarrhoea is defined as stool volume of more than 10 grams $/ \mathrm{kg} /$ day in infants and toddlers, or more than 200 grams/day in older children for more than 14 days. This typically translates to persistent loose or watery stools occurring at least three times a day, where the change in stool consistency is more important than stool frequency. Some authors make a distinction between chronic diarrhoea, which they define as having a gradual onset, from persistent diarrhoea, which they define as having a sudden onset. However, it is frequently difficult to identify the time of onset of the diarrhoea and delineation of the two entities can be problematic. Chronic diarrhoea is a common condition. Diarrhoea lasting more than two to four weeks occurs in up to 3 to 5 percent of the population worldwide. It is generally more frequent in males, with a male-to-female ratio of 1.2 to $2.6: 1$ in the age range of 6 to 24 months. 
In the developed world, the prevalence of chronic diarrhoea is substantially lower. In the United States, there is approximately one case of persistent diarrhoea per five person-years in infants and young children. Most of these cases are self-limited, with fewer than 28 percent presenting for medical care. Fewer than 100 per 10,000 children are hospitalized in the United States for diarrhoeal disease, and this figure includes many cases of acute diarrhoea.

\section{Classification based on pathophysiology}

\subsection{Secretory diarrhoea}

Secretory diarrhoea occurs when there is active secretion of water into the gut lumen.

This type of diarrhoea is often caused by a secretagogue, such as cholera toxin, binding to a receptor on the surface epithelium of the bowel and thereby stimulating intracellular accumulation of cyclic adenosine monophosphate or cyclic guanosine monophosphate. Also there are many other infectious and non-infectious causes. Examples of the latter include those mediated by gastrointestinal peptides (such as vasoactive intestinal peptide and gastrin). Certain substances, such as bile acids, fatty acids, and laxatives, also can produce a secretory diarrhoea, as can congenital problems (eg, congenital chloride diarrhea). Diarrhoea not associated with an exogenous secretagogue may also have a secretory component (congenital microvillus inclusion disease). Secretory diarrhoea tends to be watery and of large volume; the osmolality of the stool can be accounted for by the presence of electrolytes. Secretory diarrhoea generally persists even when no feedings are given by mouth.

\subsection{Osmotic diarrhoea}

This occurs after ingestion of a poorly absorbed solute. The solute may be one that is normally not well absorbed such as magnesium, phosphate, lactulose, and sorbitol or one that is not well absorbed because of a disorder of the small bowel (lactose with lactase deficiency or glucose with rotavirus diarrhoea). This results in a higher than normal concentration of the solute in the gut lumen, altering the gradient of water absorption toward fluid retention in the intestinal lumen. Enteric infections that cause damage to intestinal epithelial cells leading to malabsorption may cause diarrhoea with an osmotic component. Rotavirus and shigella are examples. Rotavirus selectively invades mature enterocytes causing a disruption of absorptive capacity. Shigella produces a "shiga" toxin which can cause villous cell destruction leading to malabsorption.

Malabsorbed carbohydrate is fermented in the colon, and short-chain fatty acids (SCFAs) are produced. Although SCFAs can be absorbed in the colon and used as an energy source, the net effect is to increase the osmotic solute load. This form of diarrhoea is usually of lesser volume (quantity) than secretory diarrhoea and stops with fasting. The osmolality of the stool will not be explained by the electrolyte content, because another osmotic component is present. Motility disorders can be associated with rapid or delayed transit and are not generally associated with large-volume diarrhoea. Slowed motility can be associated with bacterial overgrowth as a cause of diarrhoea.

\subsection{Inflammatory}

Diarrhoea can be caused by intestinal inflammation. Exudation of mucus, protein, and blood into the gut lumen leads to water and electrolyte loss and subsequent diarrhoea. 
The most common cause of inflammatory diarrhoea is infection. The initial event in the pathogenesis of acute infection is the ingestion of the offending organism. After ingestion, the organism colonizes the intestinal epithelium and adheres to the enterocyte. One of two pathways are generally followed depending upon the offending organism, either mucosal invasion or production of an enterotoxin.

Intestinal inflammation can also be caused by chronic diseases, such as inflammatory bowel disease and celiac disease. It can also be caused by tuberculosis, colon cancer, and enteritis. Diarrhoea in these disorders is multifactorial but is due in part to the mucosal inflammation, which leads to malabsorption. Malabsorbed substances produce an osmotic load in the gut lumen resulting in diarrhoea. Several bacterial infections of the gastrointestinal tract produce diarrhoea secondary to preformed toxins. Examples include the enterotoxins produced by Clostridia perfringens and Clostridia difficile, and the shiga-like toxins of Escherichia coli, Staphylococcus aureus, and Shigella species. Viral enterotoxins also have been described. As an example, rotavirus produces a viral enterotoxin, the non-structural glycoprotein (NSP4). NSP4 causes calcium-dependent transepithelial chloride secretion from the crypt cells, with resultant secretory diarrhoea.

\subsection{Impaired motility}

Motility disorders are relatively uncommon causes of acute diarrhoea. Changes in gastrointestinal motility can influence absorption. This could be hypermotility or hypomotility. Hypermotility is caused by the rapid movement of food through the intestines. If the food moves too quickly through the gastrointestinal tract, there is no enough time for sufficient nutrients and water to be absorbed. Hypermotility can be observed in people who have had portions of their bowel removed, allowing less total time for absorption of nutrients. Motility related diarrhoea can also be due to a vagotomy or diabetic neuropathy, or a complication of menstruation. Hyperthyroidism can produce hypermotility and lead to pseudodiarrhoea and occasionally real diarrhoea. This type of diarrhoea can be treated with antimotility agents (such as loperamide).

Hypomotility, or the severe impairment of intestinal peristalsis, results in stasis, with subsequent inflammation, bacterial overgrowth, and secondary bile acid deconjugation and malabsorption.

\section{Classification based on systemic diseases}

\subsection{Infectious causes}

\subsubsection{Postenteritis syndrome}

Most enteric infections in otherwise healthy children resolve within 14 days and do not develop into a chronic diarrhoeal illness. However, in a minority of patients, an acute gastroenteritis can trigger persistent diarrhoea by causing mucosal damage to the small intestine, termed a "postenteritis syndrome". The mechanisms underlying this syndrome are not fully understood. Contrary to previous hypotheses, sensitization to food antigens and secondary disaccharidase deficiency, including lactase deficiency (causing lactose intolerance), are uncommon. Therefore, international guidelines discourage the use of hypoallergenic or diluted milk formulas during acute gastroenteritis. Recurrent or sequential enteric infections may be responsible for some of these cases. In some cases, treatment with probiotic bacteria may facilitate recovery from postenteritis syndrome. 


\subsubsection{Bacterial infection}

In immunocompromised patients, common infectious causes of acute diarrhoea, such as Campylobacter or Salmonella, can cause persistent diarrhoea. Chronic infections with these pathogens are uncommon in immunocompetent hosts. Bacterial cultures should be part of the initial diagnostic evaluation for all patients if the stool contains blood, or for immunocompromised patients regardless of fecal blood.

In children recently treated with antibiotics, Clostridium difficile may cause a colitis characterized by "pseudomembrane" formation. The enzyme immunoassay available in most laboratories detects $\mathrm{C}$. difficile toxins $\mathrm{A}$ and $\mathrm{B}$ with high specificity but only moderate sensitivity. Polymerase chain reaction (PCR) based diagnostic methods can enhance the detection rate.

Enterotoxigenic strains of Staphylococcus aureus typically cause acute gastrointestinal symptoms in children or adults, due to the effects of ingested pre-formed toxin produced in contaminated food.

\subsubsection{Parasitic infections}

Intestinal parasites sometimes cause diarrhoea especially among children in developing countries. However, they are an uncommon cause of chronic diarrhoea in developed countries, except among individuals with an immunodeficiency. Specific antigen assays for Giardia and examination from the stool for parasites is imperative for children with known immunodeficiencies or with a history of travel to endemic areas. An step in the evaluation of immunocompetent children if initial testing fails to determine a cause of the chronic diarrhoea.

When a specific parasite is identified, treatment with specific medications is generally indicated, although the organism may not always be the cause of the diarrhoea. Empiric therapy for enteric pathogens is generally not advisable, except in cases with special characteristics in developing countries.

\subsection{Syndromic persistent diarrhoea}

Occasionally children in developed countries will develop a pattern in which enteric infection triggers a cycle of undernutrition, immune compromise and re-infection, resembling the syndromic persistent diarrhoea that is more commonly seen in developing countries. This pattern is uncommon in developed countries except in children with an underlying immunodeficiency.

\subsubsection{Immune deficiency}

Chronic diarrhoea may present as a complication of a known immune deficiency such as HIV disease. In this case, the evaluation should focus on potential infectious causes of the diarrhoea, particularly parasites and opportunistic infections such as Cryptosporidium, Isospora, and Cyclospora. These children also are at risk for persistent infectious pathogens that typically cause acute diarrheas, such as rotavirus.

Chronic diarrhoea also may be a presenting symptom of immune deficiency in a child. When a patient is infected with an unusual pathogen, or has multiple or recurrent infections of the gastrointestinal tract or elsewhere, further evaluation for immune deficiency is required. In rare instances, live vaccines may call attention to the potential diagnosis of 
immunodeficiency by inducing chronic infection. As an example, vaccine-acquired chronic rotavirus diarrhoea has been observed in infants with severe combined immunodeficiency

\subsection{Abnormal immune response}

\subsubsection{Celiac disease}

Celiac disease (also known as gluten-sensitive enteropathy or nontropical sprue) is an immune-mediated inflammation of the small intestine caused by sensitivity to dietary gluten and related proteins in genetically sensitive individuals. The disorder is common, occurring in 0.5 to 1 percent of the general population in most countries. Celiac disease often presents as chronic diarrhoea, with or without malnutrition, during late infancy or early childhood.

\subsubsection{Inflammatory bowel disease}

\section{Ulcerative colitis and Crohn's disease}

These are idiopathic chronic inflammatory diseases of the bowel. These disorders typically present with gradual onset of chronic diarrhoea, with or without blood, from mid-childhood through adulthood.

\section{Allergic enteropathy}

An abnormal immune response to food proteins can cause a proctitis/colitis or an enteropathy. The former tends to present as bloody diarrhoea and is frequently triggered by cow's milk protein in infants. The latter presents as non bloody diarrhoea and/or failure to thrive.

\section{Eosinophilic gastroenteritis}

This is an incompletely understood disorder that is sometimes but not always associated with an identifiable dietary antigen. Approximately one-half of patients have allergic disease, such as asthma, defined food sensitivities, eczema, or rhinitis; some patients have elevated serum IgE levels; rare patients have IgE antibodies directed against specific foods.

\section{Microscopic and collagenous colitis}

Microscopic colitis typically presents with chronic watery non bloody diarrhoea. It typically occurs in middle-aged adults, but occasionally presents in children. The endoscopy is grossly normal, but histopathology reveals abnormal inflammatory findings, characterized by a collagenous colitis or lymphocytic colitis, sometimes with an eosinophilic infiltrate. In some cases, this disorder may represent an overlap with the eosinophilic gastroenteropathies.

Collagenous colitis is a related form of colitis that has been reported in a few children. The colon appears grossly normal, but biopsies show a thickened subepithelial collagenous band in the colonic mucosa.

\section{Autoimmune enteropathies}

Autoimmune enteropathies are rare disorders that may present as severe diarrhoea during infancy or toddler hood. The diarrhoea may be isolated, or may occur in association with diabetes mellitus as part of the IPEX syndrome (Immune dysregulation, Polyendocrinopathy and Enteropathy, X-linked), which is associated with mutations in the 
FOXP3 gene. IPEX is characterized by chronic diarrhoea, which usually begins in infancy, dermatitis, autoimmune endocrinopathy (diabetes mellitus, thyroiditis).

Autoimmune polyendocrine syndrome 1 (APS-1), also known as autoimmune polyendocrinopathy-candidiasis ectodermal dystrophy (APECED), is one of several autoimmune disorders caused by mutations in the autoimmune regulator gene (AIRE). Features include hypoparathyroidism and adrenal insufficiency, and about 25 percent of patients develop autoimmune enteritis.

\subsubsection{Maldigestion of fat}

\section{Cystic fibrosis}

Cystic fibrosis is the most common cause of pancreatic exocrine insufficiency in children. The disease may present at birth with meconium ileus, or may be suggested later by gastrointestinal symptoms of fat malabsorption, failure to thrive, rectal prolapse (particularly in the setting of diarrhoea) or pulmonary symptoms.

\section{Other causes of pancreatic insufficiency}

Other causes of pancreatic exocrine insufficiency include Shwachman-Diamond syndrome (associated with bone marrow failure and skeletal abnormalities), and two rare disorders, Pearson syndrome and Johanson-Blizzard syndrome.

\section{Cholerheic diarrhoea}

Patients who have undergone resection of the terminal ileum have impaired absorption of bile acids. If sufficient bile acids enter the colon, they may cause a secretory diarrhoea.

Similarly, patients who have had a cholecystectomy can develop cholerheic diarrhoea because the continuous drainage of bile into the small bowel may overcome the terminal ileum's reabsorptive capacity.

\section{Gastrointestinal protein loss}

Signs and symptoms of gastrointestinal protein loss include hypoalbuminemia and reduced concentrations of serum immune globulins. When severe, clinically evident edema is present.

\section{Mucosal disease}

Many diseases affecting the intestinal mucosa may cause excessive loss of protein through the gastrointestinal tract. Protein losses may be caused by inflammatory exudation through mucosal erosions (eg, inflammatory bowel disease), or to increased mucosal permeability without erosions (eg, celiac disease). In most cases the protein loss will be accompanied by other signs and symptoms pointing to the cause of the diarrhoea.

\section{Lymphatic obstruction}

Obstruction of the intestinal lymphatic impairs lymph flow and increases pressure in the intestinal lymphatics. This leads to leakage of lymph into the intestinal lumen, reduced recirculation of intestinal lymphocytes into the peripheral circulation, and decreased absorption of fat-soluble vitamins.

Primary intestinal lymphangiectasia is characterized by diffuse or localized ectasia of enteric lymphatics. 
Secondary intestinal lymphangiectasia may be caused by cardiac diseases, and chemotherapeutic, infectious, or toxic substances that are associated with inflammatory processes that cause retroperitoneal lymph node enlargement, portal hypertension or hepatic venous outflow obstruction.

\section{Bowel obstruction or dysmotility}

Partial bowel obstruction or dysmotility may present with diarrhoea.

Hirschsprung's disease - This disorder may present with dysmotility and diarrhoea, and may progress to life-threatening toxic megacolon.

Intestinal pseudo obstruction - This disorder of intestinal motility typically presents with constipation, but patients also may have periods of diarrhoea, particularly if bacterial overgrowth supervenes.

\section{Classification based on congenital disorders}

\subsection{Congenital secretory and osmotic diarrhoeas}

Congenital diarrhoea can be caused by a variety of inherited disorders that disrupt nutrient digestion, absorption, or transport, enterocyte development and function, or entero endocrine function. Specific genes have been identified for some of these disorders.

\section{Secretory diarrhoea}

Congenital secretory diarrhoea is rare and is characterized by profuse watery diarrhoea beginning at birth. The diarrhoea is so watery that it may be mistaken for urine in the diaper.

\section{Congenital chloride diarrhoea}

Congenital chloride diarrhoea is caused by a variety of mutations in the SLC26A3 (solutelinked carrier family 26 member A3) gene, which encodes for an epithelial anion exchanger. Most reported cases are in Finland, Poland, or Arab populations. Because of excessive fecal losses of fluid and electrolytes, affected individuals present in the neonatal period with hyponatremia, hypochloremia, and metabolic alkalosis; there may be a history of polyhydramnios. The diagnosis of CCD is based on the finding of excessive fecal secretion of chloride, in which the chloride concentration exceeds the concentration of cations. However, this finding is only reliable when the patient is in fluid and electrolyte balance. In the untreated patient, the volume and chloride content of the diarrhoea may be artificially reduced.

Congenital sodium diarrhoea - Congenital sodium diarrhoea (CSD) has a syndromic form which includes choanal or anal atresia and is associated with mutations in the SPINT2 gene, which are not seen in patients with isolated CSD. The stool is alkaline and fecal sodium concentrations are high; metabolic acidosis and hyponatremia are typically present; there may be a history of polyhydramnios.

Microvillus inclusion disease - Microvillus inclusion disease (MID) also called microvillus atrophy) was associated with mutations in type $\mathrm{Vb}$ myosin motor protein (MYO5B) in several kindreds. The disorder typically presents with intractable secretory diarrhoea shortly after birth, rapidly progressing to hypotonic dehydration and metabolic acidosis. A milder form of MID presents a few months later.

Tufting enteropathy - Tufting enteropathy (also known as intestinal epithelial cell dysplasia) appears to be caused by mutations in the EpCAM (epithelial cell adhesion 
molecule) gene. The disorder presents with secretory diarrhoea shortly after birth; the diarrhoea volume is often less than in MID, and may partially respond to fasting.

Epithelial tufts also may be observed in congenital diarrhoea associated with other gene defects, such as in the case of SPINT2-related disease. In such cases, genetic testing can be particularly helpful to define the diagnosis, prognosis, and potential therapy.

Enteric anendocrinosis - Enteric anendocrinosis (also known as congenital malabsorptive diarrhoea 4) is caused by mutations in neurogenin-3 (NEUROG3) and is associated with a paucity of enteroendocrine cells in the pancreas and intestine. It is characterized by an osmotic diarrhoea and later development of insulin-deficient diabetes, without anti-islet cell antibodies. Enteroendocrine and/or enterochromaffin cell paucity can be caused by a variety of other mechanisms.

Osmotic diarrhoea - In contrast with the secretory diarrhoea described above, congenital osmotic diarrhoea ceases during fasting or upon exclusion of certain dietary components that are maldigested by the patient.

Glucose-galactose malabsorption - Glucose-galactose malabsorption presents with severe life-threatening diarrhoea and dehydration during the neonatal period, caused by deficiency in the intestinal sodium/glucose transporter. Patients are symptomatic as long as their diet includes lactose or it's hydrolysis products, glucose and galactose. The diagnosis is suspected if the diarrhoea resolves promptly when these sugars are eliminated, and confirmed by a positive glucose breath hydrogen test and normal intestinal biopsy.

Congenital sucrase-isomaltase deficiency - Congenital sucrase-isomaltase deficiency is rare in most populations, except among individuals of Eskimo or Canadian Native descent. Infants are asymptomatic if their diet contains only lactose (eg, exclusively breast-fed infants), but typically develop chronic diarrhoea after sucrose-containing formulas or foods are introduced. A number of mutations in the gene encoding sucrase-isomaltase have been described in affected individuals.

\section{Steatorrhoea}

Defects in pancreatic enzyme activity and lipid trafficking tend to present with chronic lowvolume diarrhoea and failure to thrive during infancy, caused by fat malabsorption. These include abetalipoproteinemia and defects of bile acid absorption (eg, primary bile acid malabsorption, or of pancreatic enzyme production (eg, pancreatic lipase deficiency). Neurologic symptoms may ensue, particularly in abetalipoproteinemia.

Chylomicron retention disease (also known as Anderson disease) is characterized by failure to secrete chylomicrons across the basolateral membrane of the enterocyte. Patients generally present with fat malabsorption, steatorrhoea, and failure to thrive during infancy. The lipid distension of the enterocytes causes secondary malabsorption of carbohydrates and amino acids, which may improve with a low-fat diet.

\section{Classification based on tumors}

\subsection{Neuroendocrine tumors}

Neuroendocrine tumors affecting the gastrointestinal tract are rare in children; they tend to cause secretory diarrhoea.

Gastrinoma - In this syndrome, also known as Zollinger-Ellison syndrome, unregulated secretion of gastrin causes hypersecretion of gastric acid, with consequent peptic ulcer disease and chronic diarrhoea. Fewer than 5 percent of patients present during adolescence. The disorder may be suspected in a patient presenting with unexplained peptic ulcer 
disease and/or with a secretory diarrhoea and fat malabsorption. Fasting serum gastrin levels are elevated 5 to 10 fold.

VIPoma - Unregulated hypersecretion of vasoactive intestinal polypeptide (VIP) causes watery diarrhoea, hypokalemia, and achlorhydria. VIPomas are very rare in children, but may occur as ganglioneuromas and ganglioneuroblastomas in the sympathetic ganglia and in the adrenal glands (rather than in the pancreas where they are often found in adults).

Mastocytosis - In children, this disorder usually takes the form of cutaneous mastocytosis, consisting only of the skin lesions of urticaria pigmentosa, and is often selflimited. A few children, particularly those presenting after 2 years of age, have systemic mastocytosis, which may include histamine-induced gastric hypersecretion and chronic diarrhoea.

\section{Non specific}

\section{Factitious diarrhoea}

Factitious diarrhoea may be characterized by a true increase in stool volume, which is selfinduced (eg, laxative abuse), or the creation of an apparent increase in stool volume by the addition of various substances to the stool (eg, water or urine). Diagnosing factitious diarrhoea is often difficult and requires alertness to this possibility, exclusion of other diseases, and may be aided by specific testing.

\section{Functional diarrhoea}

Functional diarrhoea is defined as the painless passage of three or more large, unformed stools during waking hours for four or more weeks, with onset in infancy or the preschool years, and without failure to thrive or a specific definable cause. This common, benign disorder has also been termed chronic nonspecific diarrhoea of childhood or toddler's diarrhoea.

Children with functional diarrhoea usually pass stools only during waking hours. Early morning stools typically are large and semi-formed, then stools become progressively looser as the day progresses. Virtually all children develop normal bowel patterns by four years of age. In some cases, the diarrhoea is associated with excessive intake of fruit juice, sorbitol, or other osmotically active carbohydrates, and will improve when the intake of these foods is moderated. Other than this precaution, restrictions to the diet or other interventions are not necessary or helpful. In particular, restriction of dietary fat may be counter-productive.

\section{Dysentery}

This is diarrhoea with visible blood in the faeces of any duration. Important effects of dysentery include anorexia, rapid weight loss and damage to the intestinal mucosa by the invasive bacteria. A number of other complications may occur. The most important cause of acute dysentery is Shigella; other causes are Campylobacter jejuni and, infrequently, enteroinvasive E. coli or Salmonella. Entamoeba hystolitica can cause serious dysentery in young adults but is rarely a cause of dysentery in young children.

\section{Irritable bowel syndrome}

Another possible type of diarrhoea is irritable bowel syndrome (IBS) which usually presents with abdominal discomfort relieved by defecation and unusual stool (diarrhoea or 
constipation) for at least 3 days a week over 3 months. About $30 \%$ of patients with diarrhoea-predominant IBS have bile acid malabsorption. Symptoms of diarrhoeapredominant IBS can be managed through a combination of dietary changes, soluble fiber supplements, and/or medications such as loperamide or codeine.

\section{References}

[1] Black, RE, Morris SS, Bryce J: Where and why are 10 million children dying every year? Lancet 2003; 361: 2226-2234.

[2] Mortality and Burden of Disease Estimates for WHO Member States in 2004". World Health Organization.

http://www.who.int/entity/healthinfo/global_burden_disease/gbddeathdalycou ntryestimates 2004.

[3] Navaneethan U, Giannella RA. "Mechanisms of infectious diarrhea". Nature Clinical Practice. Gastroenterology \& Hepatology 2008; 5 (11): 637-47.

[4] WHO | Diarrhoeal Diseases (Updated February 2009)". World Health Organization. http://www.who.int/vaccine_research/diseases/diarrhoea.

[5] A.I. Frank-Briggs, A.R. Nte. Diarrhoeal Disease: The Trend In A Southern Nigerian City West African Journal of Medicine 2009; 28(4): 211-215.

[6] Patel MM, Hall AJ, Vinjé J, Parashar UD (January 2009). "Noroviruses: a comprehensive review". Journal of Clinical Virology 44 (1): 1-8.

[7] Greenberg HB, Estes MK. "Rotaviruses: from pathogenesis to vaccination". Gastroenterology 2009; 136 (6): 1939-1951.

[8] Mitchell DK. "Astrovirus gastroenteritis". The Pediatric Infectious Disease 2002; 21 (11): 1067-1069.

[9] Frank- Briggs A.I, George I.O. Knowledge of use of zinc in the treatment of Diarrhoeal Diseases among practicing Doctors: The Port Harcourt Experience. The Nigeria Health Journal, 2005; (5): 314-317.

[10] Viswanathan VK, Hodges K, Hecht G. "Enteric infection meets intestinal function: how bacterial pathogens cause diarrhoea". Nature Reviews. Microbiology2009; 7 (2): 110-119.

[11] Rupnik M, Wilcox MH, Gerding DN. "Clostridium difficile infection: new developments in epidemiology and pathogenesis". Nature Reviews. Microbiology 2009;7 (7): 526-536.

[12] Kiser JD, Paulson CP, Brown C. "Clinical inquiries. What's the most effective treatment for giardiasis?". The Journal of Family Practice 2008; 57 (4): 270-272.

[13] Dans L, Martínez E. "Amoebic dysentery". Clinical Evidence 2006; (15): 1007-1013.

[14] Alam NH, Ashraf H. "Treatment of infectious diarrhea in children". Paediatr Drugs 2003; 5 (3): 151-165.

[15] Longstreth GF, Thompson WG, Chey WD, Houghton LA, Mearin F, Spiller RC. "Functional bowel disorders". Gastroenterology 2006; 130 (5): 1480-1491.

[16] Wedlake, L; A'Hern, R, Russell, D, Thomas, K, Walters, JR, Andreyev, HJ. "Systematic review: the prevalence of idiopathic bile acid malabsorption as diagnosed by SeHCAT scanning in patients with diarrhoea-predominant 
irritable bowel syndrome.". Alimentary pharmacology \& therapeutics 2009; 30 (7): 707-17.

[17] Ejemot RI, Ehiri JE, Meremikwu MM, Critchley JA. Hand washing for preventing diarrhoea. Cochrane Database of Systematic Reviews 2008, Issue 1. Art. No.: CD004265.

[18] King CK, Glass R, Bresee JS, Duggan C. "Managing acute gastroenteritis among children: oral rehydration, maintenance, and nutritional therapy". MMWR Recomm Rep 2003; 52 (RR-16): 1-16.

[19] Schiller LR. "Management of diarrhea in clinical practice: strategies for primary care physicians". Rev Gastroenterol Disord.2007; 7 Suppl 3: S27-38.

[20] Dryden MS, Gabb RJ, Wright SK. "Empirical treatment of severe acute communityacquired gastroenteritis with ciprofloxacin". Clin. Infect. Dis. 1996; 22 (6): 1019_ 1025.

[21] de Bruyn G. "Diarrhoea in adults (acute)". Clin Evid (Online) 2008.

[22] DuPont HL, Ericsson CD, Farthing MJ, Gorbach S, Pickering LK. "Expert review of the evidence base for self-therapy of travelers' diarrhea". J Travel Med 2009; 16 (3): 161171.

[23] Pawlowski SW, Warren CA, Guerrant R. "Diagnosis and treatment of acute or persistent diarrhea". Gastroenterology 2009; 136 (6): 1874-1886.

[24] Lazzerini M, Ronfani L. Oral zinc for treating diarrhoea in children. Cochrane Database of Systematic Reviews 2008, Issue 3. Art. No.: CD005436.

[25] Kale-Pradhan PB, Jassal HK, Wilhelm SM. "Role of Lactobacillus in the prevention of antibiotic-associated diarrhea: a meta-analysis". Pharmacotherapy 2010; 30 (2): 119126.

[26] Guarino A, Albano F, Guandalini S, Working Group on Acute Gastroenteritis. Oral rehydration: toward a real solution. J Pediatr Gastroenterol Nutr 2001; 33 Suppl 2:S2.

[27] Boschi-Pinto C, Velebit L, Shibuya K. Estimating child mortality due to diarrhoea in developing countries. Bull World Health Organ 2008; 86:710.

[28] Kosek M, Bern C, Guerrant RL. The global burden of diarrhoeal disease, as estimated from studies published between 1992 and 2000. Bull World Health Organ 2003; 81:197.

[29] Bryce J, Boschi-Pinto C, Shibuya K, Black RE and the WHO Child Health Epidemiology Reference Group. WHO estimates of the causes of death in children. Lancet 2005; 365:1147.

[30] Ryan ET, Dhar U, Khan WA, Salam WA, Faruque ASG, Fuchs GJ. Mortality, morbidity, and microbiology of endemic cholera among hospitalized patients in Dhaka, Bangladesh. Am J Trop Med Hyg 2000; 63:12.

[31] Karim AS, Akhter S, Rahman MA, Nazir MF. Risk factors of persistent diarrhea in children below five years of age. Indian J Gastroenterol 2001; 20:59.

[32] Binder HJ. Causes of chronic diarrhea. N Engl J Med 2006; 355:236.

[33] Ochoa TJ, Salazar-Lindo E, Cleary TG. Management of children with infectionassociated persistent diarrhea. Semin Pediatr Infect Dis 2004; 15:229. 
[34] Wedlake L, A'Hern R, Russell D, Thomas K, Walters JR, Andreyev HJ. "Systematic review: the prevalence of idiopathic bile acid malabsorption as diagnosed by SeHCAT scanning in patients with diarrhoea-predominant irritable bowel syndrome". Alimentary pharmacology \& therapeutics 2009; 30 (7): 707-17. 


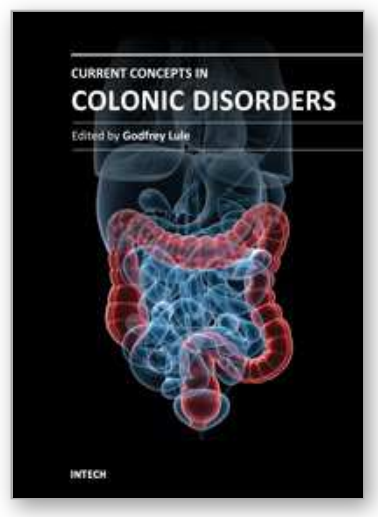

\author{
Current Concepts in Colonic Disorders \\ Edited by Dr. Godfrey Lule
}

ISBN 978-953-307-957-8

Hard cover, 276 pages

Publisher InTech

Published online 05, January, 2012

Published in print edition January, 2012

The 21 st Century has seen a resurgence of research of the gastrointestinal tract, especially since it was established that it plays a central role as an immune system organ and consequentially has a huge impact on causation, impact and transmission of most human ailments. New diseases such as the Acquired Immunodeficiency Syndrome, hepatitis and tumours of the gastrointestinal tract have emerged and they are currently subjects of intensive research and topics of scientific papers published worldwide. Old diseases like diarrhea have become extremely complex to diagnose with new and old pathogens, drugs, tumours and malabsorptive disorders accounting for the confusion. This book has set out algorithms on how to approach such conditions in a systematic way both to reach a diagnosis and to make patient management cheaper and more efficient. "Current Concepts in Colonic Disorders" attempts to put all the new information into proper perspective with emphasis on aetiopathogenesis and providing rational approach to management of various old and new diseases. As the book editor, I have found this first edition extremely interesting and easy to understand. Comments on how to improve the content and manner of presentation for future editions are extremely welcome.

\title{
How to reference
}

In order to correctly reference this scholarly work, feel free to copy and paste the following:

Angela Ine Frank-Briggs (2012). Introduction and Classification of Childhood Diarrhoea, Current Concepts in Colonic Disorders, Dr. Godfrey Lule (Ed.), ISBN: 978-953-307-957-8, InTech, Available from: http://www.intechopen.com/books/current-concepts-in-colonic-disorders/introduction-and-classification-ofchildhood-diarrhoea

\section{INTECH}

open science | open minds

\section{InTech Europe}

University Campus STeP Ri

Slavka Krautzeka 83/A

51000 Rijeka, Croatia

Phone: +385 (51) 770447

Fax: +385 (51) 686166

www.intechopen.com

\section{InTech China}

Unit 405, Office Block, Hotel Equatorial Shanghai

No.65, Yan An Road (West), Shanghai, 200040, China

中国上海市延安西路65号上海国际贵都大饭店办公楼 405 单元

Phone: +86-21-62489820

Fax: +86-21-62489821 
(C) 2012 The Author(s). Licensee IntechOpen. This is an open access article distributed under the terms of the Creative Commons Attribution 3.0 License, which permits unrestricted use, distribution, and reproduction in any medium, provided the original work is properly cited. 